\title{
Experimental Study on Fly-Ash Aggregate as a Lightweight Filler in a Structural Element
}

\author{
S. Deepasree ${ }^{1, a^{*}}$, V. Raguraman ${ }^{2, b}$ and R. Anuradha ${ }^{3, c}$ \\ ${ }^{1}$ Student- Department of Civil Engineereing Sri Shakthi Institute of Engineering and Technology, \\ Coimbatore, Tamilnadu, India \\ ${ }^{2}$ Assistant Professor- Department of Civil Engineereing Sri Shakthi Institute of Engineering and \\ Technology, Coimbatore, Tamilnadu, India \\ ${ }^{3}$ Professor and Head- Department of Civil Engineereing Sri Shakthi Institute of Engineering and \\ Technology, Coimbatore, Tamilnadu, India \\ a*deepuscool2@gmail.com, bsvs.vrr49@gmail.com, chodcivil@siet.ac.in
}

Keywords: Lightweight Structure, Fly-Ash Aggregate, Sintering Effect, Compressive Strength, Split Tensile Strength, Flexural Strength

\begin{abstract}
Light-weight structures are widely used in the construction field. Light-weight fillers such as aggregates can be used to improve weightless structures. Generally, standard aggregates cannot be used to attain the desired weight for light-weight structures. To determine a light-weight filler, the aggregates are made by using fly-ash along with cement mortar. Fly ash was collected from the Mettur Thermal power plant. Cement and fly-ash were mixed in a concrete mixer in a proportion of 30:70 with a water-cement ratio of 0.3 and it is mixed until the pellets are formed. The aggregates are replaced at different percentages such as $0 \%, 10 \%, 20 \%$, and $30 \%$ respectively to the coarse aggregate. The properties such as compressive strength, split tensile strength and flexural strength were taken. The maximum strength was attained at $30 \%$ of fly-ash aggregate with a compressive strength of $46.47 \mathrm{~N} / \mathrm{mm}^{2}$, split tensile strength of $14.85 \mathrm{~N} / \mathrm{mm}^{2}$ and flexural strength of $3.80 \mathrm{~N} / \mathrm{mm}^{2}$.
\end{abstract}

\section{Introduction}

From the coal combustion plant, the production of fly-ash is nearly $80 \%$, and bottom ash of $20 \%$ which results in nearly 500 tons [1]. The production of materials requires a large land area for disposal which results in soil contamination, water and air pollution [2-6]. In the construction field, there is a demand for utilizing a new application and technology. Likewise, industrial waste products are being used in the construction field [7-12]. The utilization of waste is generally perceived as one of the favored alternatives towards the accomplishment of a feasible turn of events [13]. Light-weight structures are preferably used than the high self-weight of concrete since such high weight units become a limiting factor in some construction fields [14-17]. Light-weight structures possess various advantages such as thinner structure and footing, reduced dimensional column and beams with the availability of large space, and easy handling of precast elements [18]. Fly ash has been used in various sectors such as cellular concrete, stabilization of soil, manufacturing of bricks, and lightweight aggregate [19]. Fly ash is effectively utilized in many construction applications such as abrasives, backfills. Manufacturing of soil products, drainage media, road base, subbase, and structural fill [20]. To advance the properties of ash, thermal methods such as autoclaving, steam process, and sintering are applied. Sintering suggests the openness of the pellet to high temperature. It has a typical source in the production of aggregates regardless of being an energy-concentrated cycle [21-25]. Fly debris can be conveyed by 
accepting palletization as a technique of joining better particles into a strong material without the application of external force which brings about the low-density weight as a result of the presence of pores [26,27]. The pellets are produced with fly debris because of the occurrence of airborne voids and these airborne voids are answerable for their retentiveness. Retentiveness has a huge role in a blend and the exhibition of the concrete [28]. Fly ash aggregates not only used for protection of environment by recycling the waste resource also to produce a light weight structure in improving the concrete properties. Bottom ash was utilized for the most part on road construction and concrete block and also applied as light weight in cement mortar [28]. In addition to that, it can also be used in coarse aggregate and fine aggregate mainly in high performance concrete [29]. High permeable bottom ash elements may lessen the shrinkage due to the utilization of those elements as a light weight in concrete. The creation of solid utilizing these aggregate is around $22 \%$ lighter and simultaneously $20 \%$ more grounded than the standard weight aggregate concrete. Drying shrinkage is found to be $32 \%$ comparatively reduced than that of ordinary concrete. This study is the first attempt in using a fly-ash pellet as a light-weight filler for the replacement of coarse aggregate.

\section{Materials and experimental methods \\ Materials \\ Cement}

The concrete paste was set up from ordinary Portland cement (OPC) with a specific gravity of 3.12. The consistent water-binder ratio of 0.55 was utilized for all blends.

\section{Fly-debris}

Fly-debris was obtained from the Mettur Thermal power plant. In addition to some potential benefits to the concrete itself, the application of fly debris as a light-weight pellet in place of natural aggregate offers a wealth of benefits both economically and environmentally.

\section{Preparation of Fly-ash pellet}

Fly Ash was obtained from Mettur nuclear energy station. Fly debris has been generated from an electrostatic precipitator in the nuclear energy station which was taken straightforwardly from the container in a dry state. It has been classified under class C-fly debris. Fly debris is usually delivered by consuming lignite or sub-bituminous coal. Concrete and fly debris were blended in a concrete blender in a proportion of 30:70 with a water binder ratio of 0.3 and the mixture is blended until the pellets are shaped. The pellets are continued drying for 3 days. After the drying stage, the pellets ought to be on restoring for 7 days. The preparation of fly ash aggregate is shown in figure 1. 


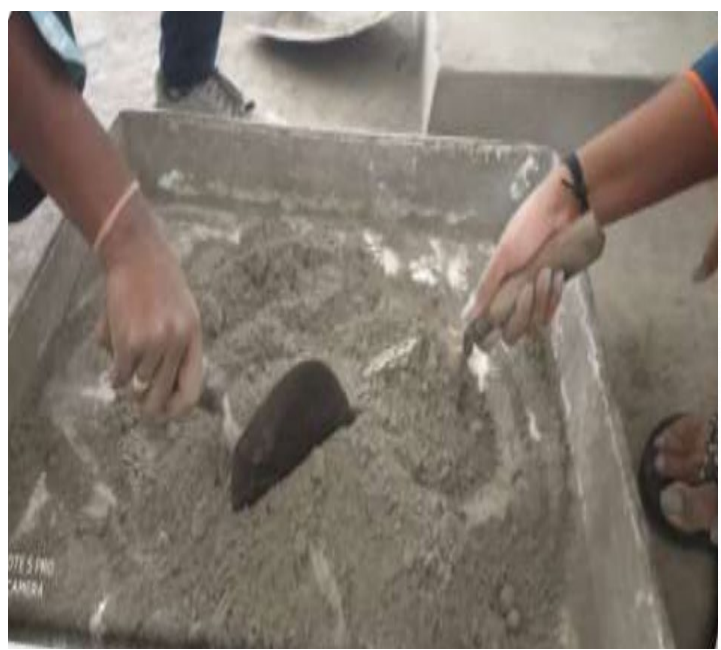

(c)

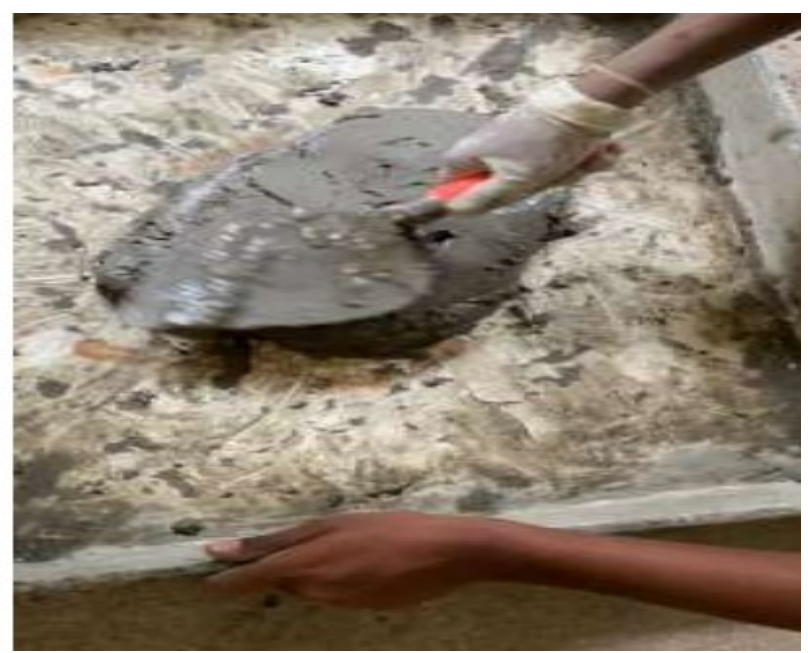

(d)

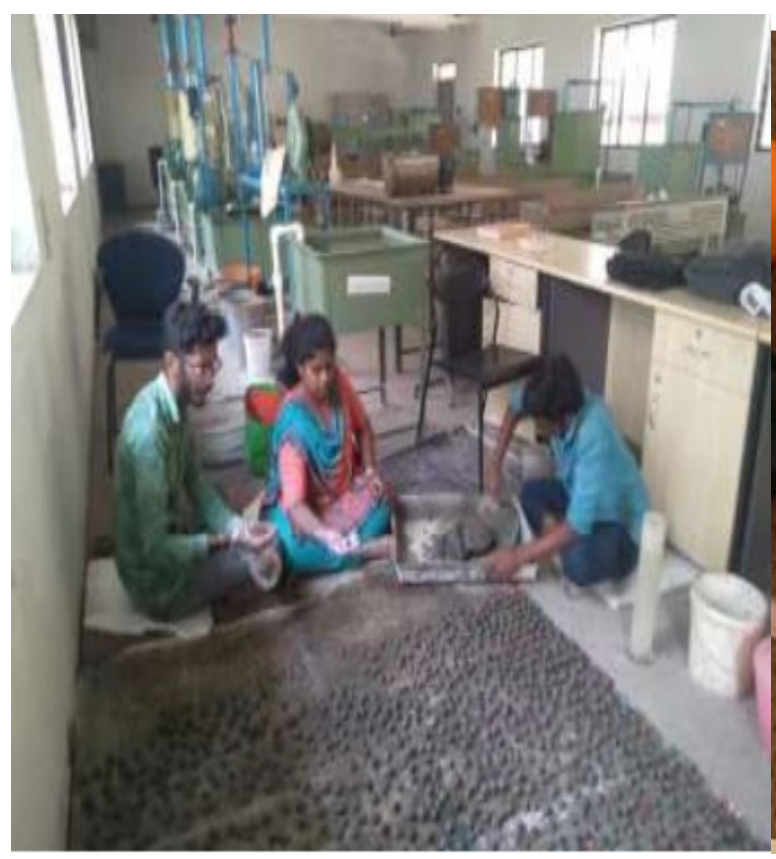

(c)

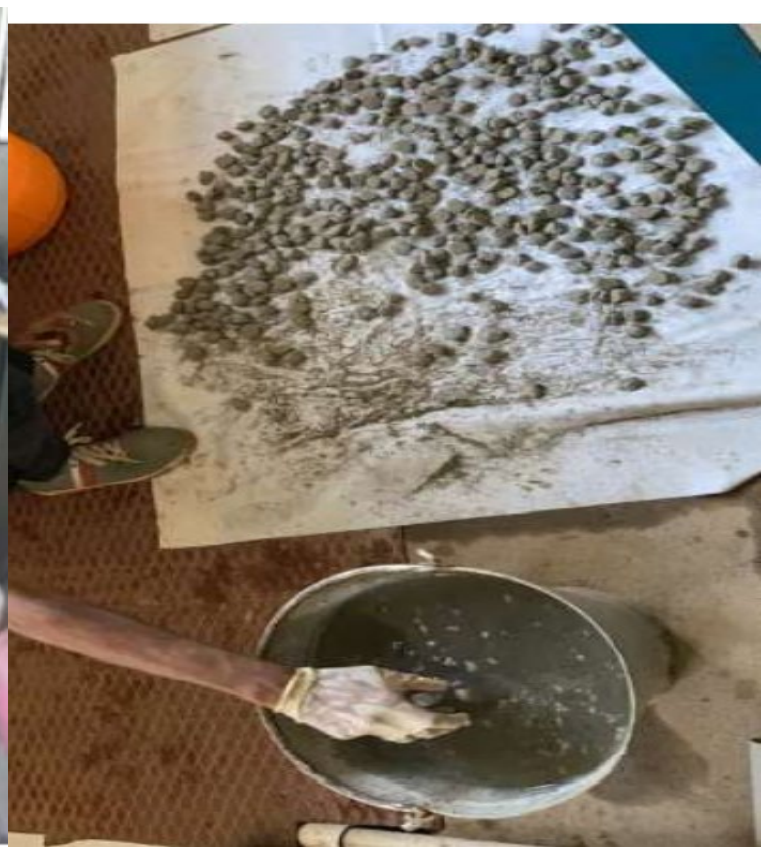

(d)

Fig. 1 Preparation of fly ash aggregate

\section{Mix Proportion}

The samples are cast in different sizes for the compressive, split tensile and flexural test in sizes of $150 \times 150 \times 150 \mathrm{~mm}, 150 \times 300 \mathrm{~mm}$, and $150 \times 150 \times 700 \mathrm{~mm}$ respectively with a water-binder ratio of 0.55 . The fly ash aggregate was replaced in different proportions such as $0 \%, 10 \%, 20 \%$, and $30 \%$ to the coarse aggregate. 


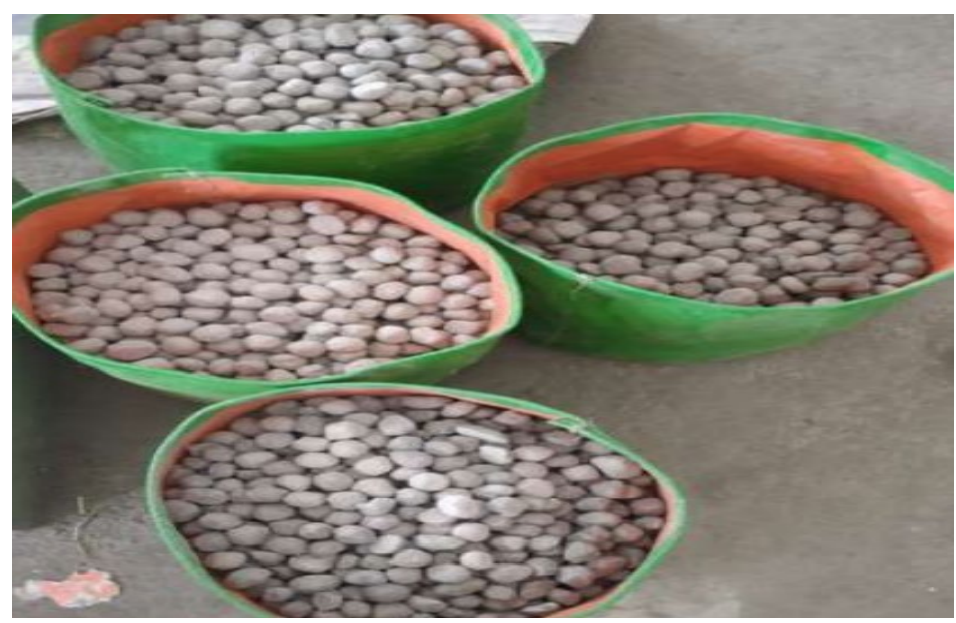

Fig. 2 Fly ash aggregate

\section{Experimental results}

Compressive strength

The concrete cube of size 150x150x150 mm was cast. The fly-ash pellets were replaced with coarse aggregate at a proportion of $0 \%, 10.0 \%, 20.0 \%$, and $30.0 \%$ respectively. The properties of concrete were tested at 7 days and 28 days. At 7 days of strength, the strength parameter was increased by $31.2 \%, 49.7 \%, 50.8 \%$ for a mix proportion of $10.0 \%, 20.0 \%$, and $30.0 \%$ respectively compared to the conventional mix. At 28 days of strength, the compressive strength was increased by $7.5 \%, 17.1 \%, 53.7 \%$ for $10.0 \%, 20.0 \%$, and $30.0 \%$ respectively compared to conventional mix as discussed in table1. The pictorial representation of the compressive strength was shown in figure 3 .

Table 1 Compressive strength of concrete

\begin{tabular}{|c|c|c|c|}
\hline \multirow{2}{*}{ S.No } & \multirow{2}{*}{$\begin{array}{c}\text { Percentage of } \\
\text { pellet }\end{array}$} & \multicolumn{2}{|c|}{ Compressive strength $\mathbf{N} / \mathbf{m m}^{\mathbf{2}}$} \\
\cline { 3 - 4 } & 0 & $\mathbf{7}$ day & $\mathbf{2 8 ~ d a y}$ \\
\hline 1 & 10 & 15.97 & 30.33 \\
\hline 2 & 20 & 20.96 & 32.5 \\
\hline 3 & 30 & 23.91 & 35.4 \\
\hline 4 & 24.01 & 46.47 \\
\hline
\end{tabular}




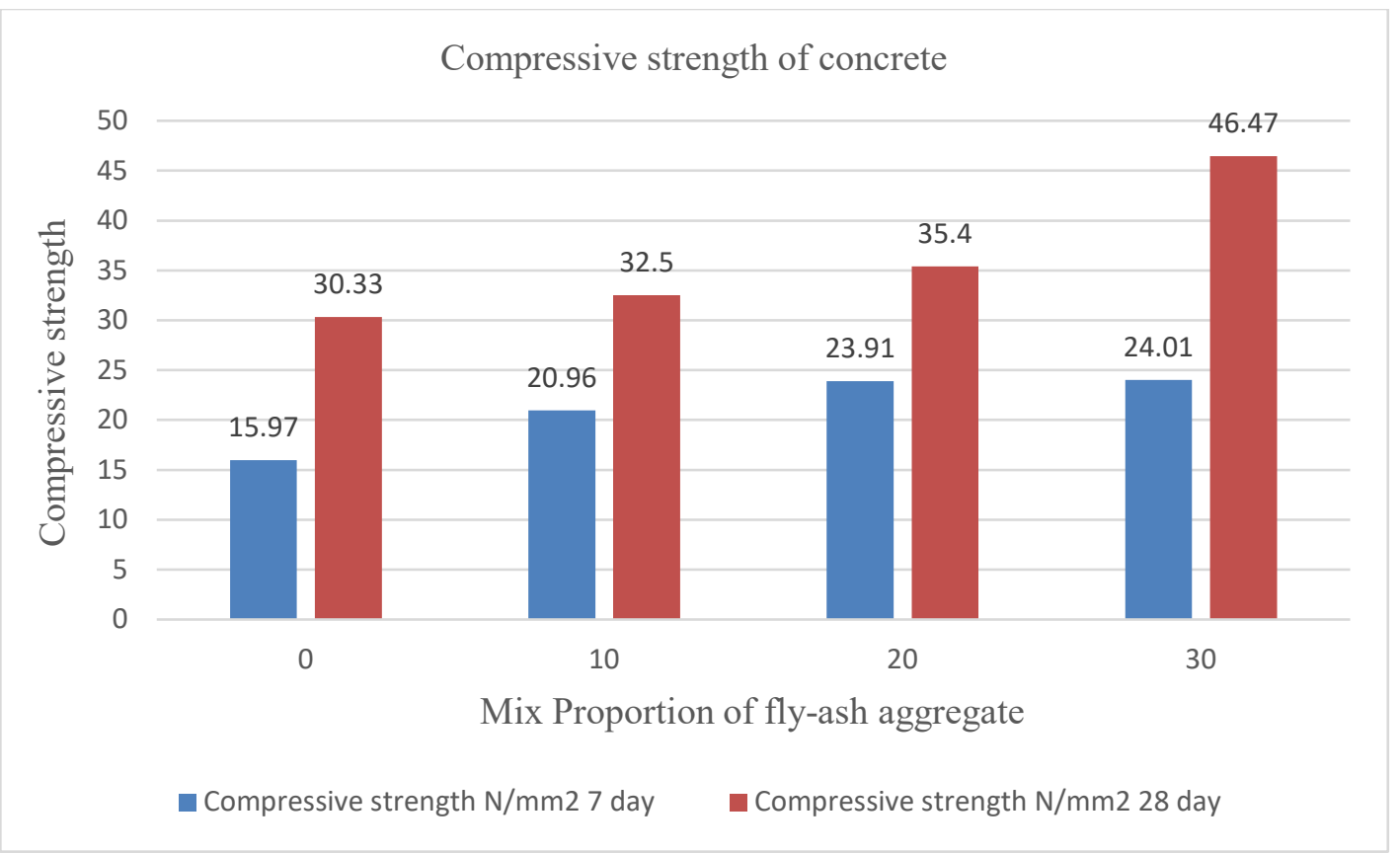

Fig. 3 Compressive strength of concrete

Split tensile strength

The concrete cylinder of size $150 \times 300 \mathrm{~mm}$ was cast. The fly-ash pellets were replaced with coarse aggregate at a proportion of $0 \%, 10.0 \%, 20.0 \%$, and $30.0 \%$ respectively. The graphical representation of the split tensile strength was shown in figure 4 . The strength parameter was tested at 7 days and 28 days. At 7 days of testing, the split tensile strength was increased by $16.7 \%$, $31.7 \%, 70 \%$ for a mix proportion of $10.0 \%, 20.0 \%$, and $30.0 \%$ respectively compared to the conventional mix. At 28 days of testing, the compressive strength was increased by $13.3 \%, 14.9 \%$, $51.5 \%$ for $10.0 \%, 20.0 \%$, and $30.0 \%$ respectively compared to the control mix as discussed in table 2.

Table 2 Split tensile strength of concrete

\begin{tabular}{|c|c|c|c|}
\hline \multirow{2}{*}{ S.No } & \multirow{2}{*}{$\begin{array}{c}\text { Percentage of } \\
\text { pellet }\end{array}$} & \multicolumn{2}{|c|}{ Split tensile strength $\mathbf{~} / \mathbf{m m}^{\mathbf{2}}$} \\
\cline { 3 - 4 } & 0 & $\mathbf{7}$ day & $\mathbf{2 8}$ day \\
\hline 1 & 10 & 6 & 9.8 \\
\hline 2 & 20 & 7 & 11.1 \\
\hline 3 & 30 & 7.9 & 11.26 \\
\hline 4 & 10.2 & 14.85 \\
\hline
\end{tabular}




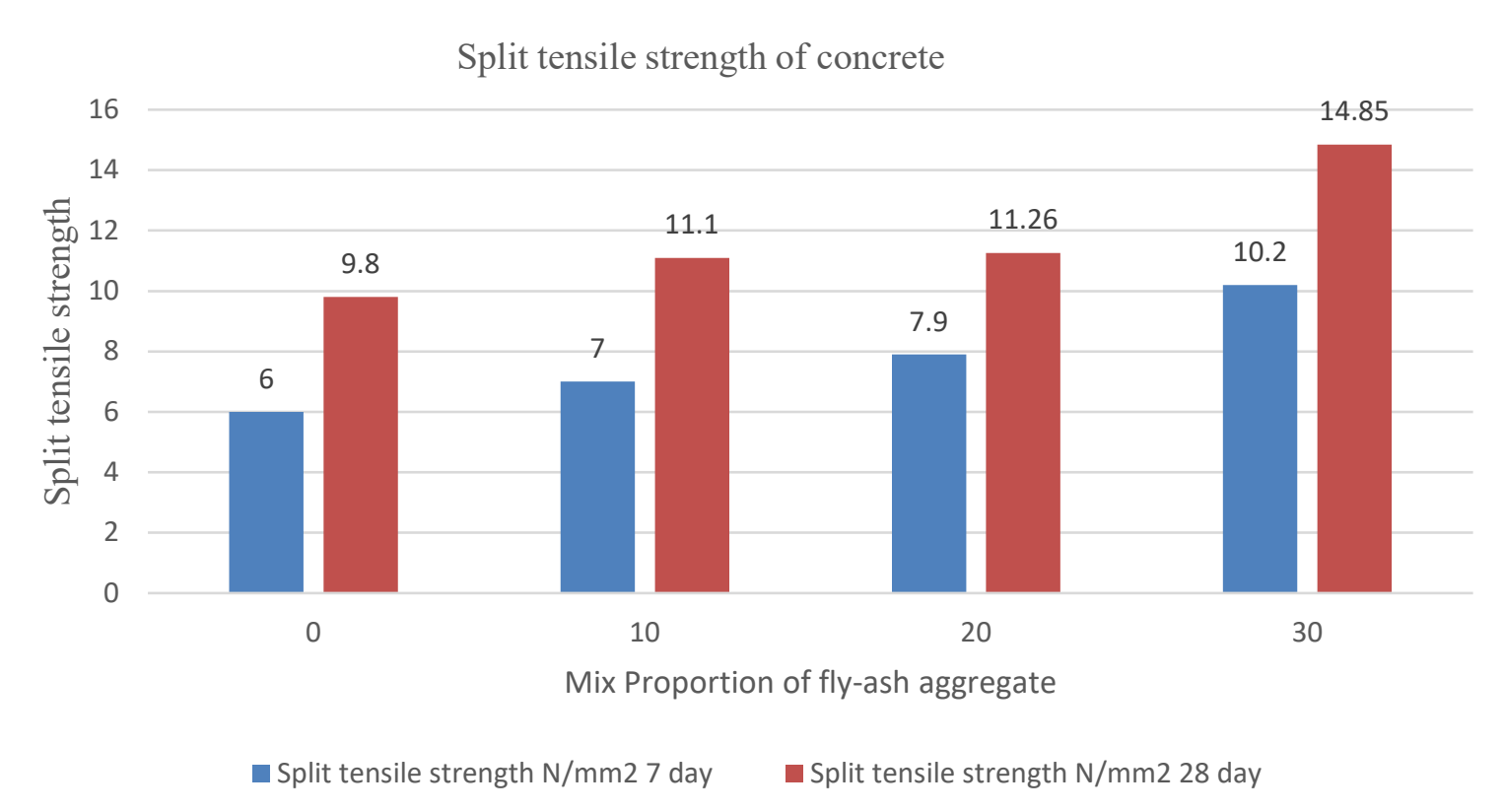

Fig.4 Split tensile strength of concrete

Flexural strength

The beam of size $750 \times 150 \times 150 \mathrm{~mm}$ was cast. The fly-ash pellets were replaced with coarse aggregate at a proportion of $0 \%, 10.0 \%, 20.0 \%$, and $30.0 \%$ respectively. The strength parameter was tested at 7 days and 28 days. At 7 days of testing, the flexural strength was increased by $4.9 \%$, $9.7 \%, 66.4 \%$ for a mix proportion of $10.0 \%, 20.0 \%$, and $30.0 \%$ respectively compared to the conventional mix. At 28 days of testing, the flexural strength was increased by $9.4 \%, 19.2 \%$, $62.4 \%$ for $10.0 \%, 20.0 \%$, and $30.0 \%$ respectively compared to the conventional mix as discussed in table 3 . The graphical representation of the flexural strength was shown in figure 5.

Table 3 Flexural strength of the beam

\begin{tabular}{|c|c|c|c|}
\hline \multirow{2}{*}{ S.No } & \multirow{2}{*}{$\begin{array}{c}\text { Percentage of } \\
\text { pellet }\end{array}$} & \multicolumn{2}{|c|}{ Flexural strength $\mathbf{N} / \mathbf{m m}^{\mathbf{2}}$} \\
\cline { 3 - 4 } & 0 & $\mathbf{7}$ day & $\mathbf{2 8}$ day \\
\hline 1 & 10 & 2.26 & 2.34 \\
\hline 2 & 20 & 2.37 & 2.56 \\
\hline 3 & 30 & 2.48 & 2.79 \\
\hline 4 & 3.76 & 3.8 \\
\hline
\end{tabular}




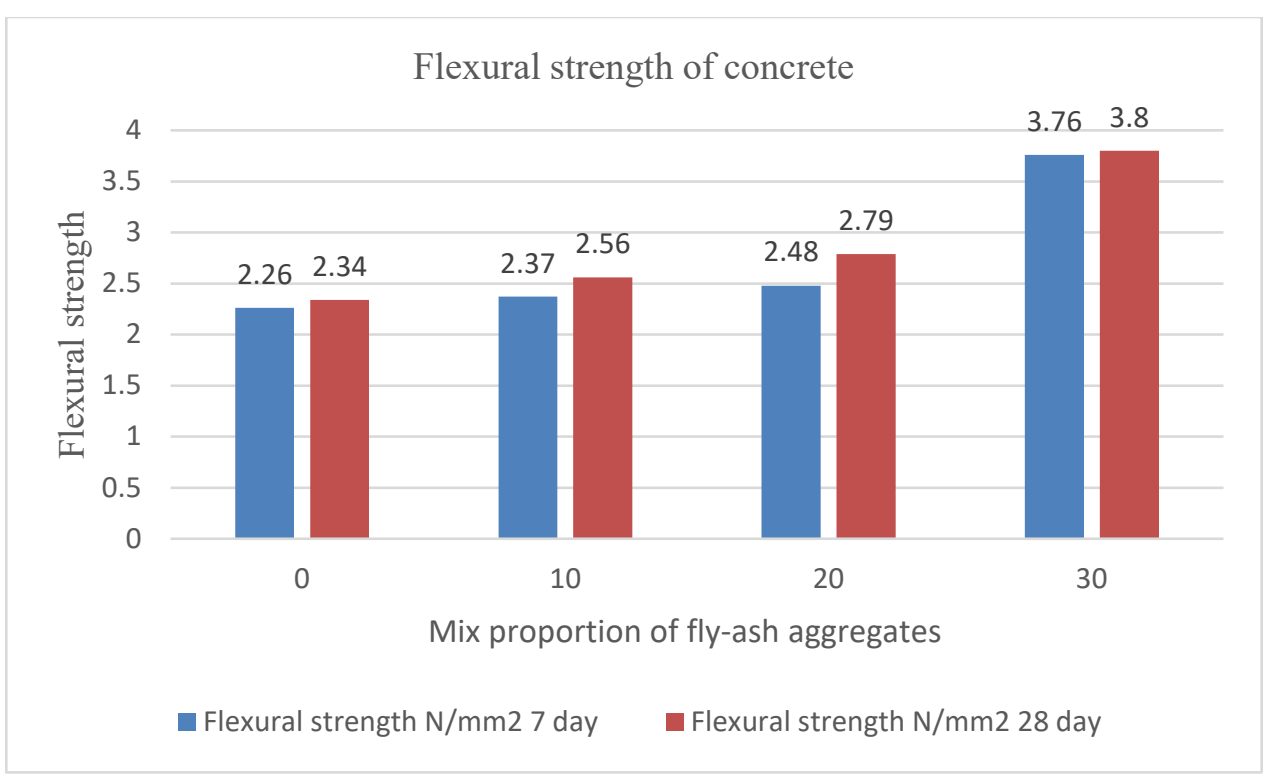

Fig. 5 Flexural strength of concrete

\section{Conclusions}

The following are the accomplishment of the study:

- Lightweight concrete is made by using a fly ash aggregate as a lightweight filler.

- The sintering effect is used to make fly-ash aggregate. Cement and fly-ash were added in a proportion of 30:70.

- The fly-ash aggregate is replaced with coarse aggregate at different proportions such as $0 \%$, $10 \%, 20 \%$, and $30 \%$ respectively.

- The optimum strength was obtained at a substitution of $30 \%$ of fly-ash pellet to the coarse aggregate.

\section{References}

[1] Acar, I.; Atalay, M.U. Characterization of sintered class F fly ashes. Fuel2013, 106, 195-203. https://doi.org/10.1016/j.fuel.2012.10.057

[2] Sokolar, R.; Smetanova, L. Dry pressed ceramic tiles based on fly ash-clay body: influence of fly ash granulometry and pentasodium triphosphate addition. Ceram. Int.2010, 36, 215-221. https://doi.org/10.1016/j.ceramint.2009.07.009

[3] Medina, A.; Gamero, P.; Querol, X.; Moreno, N.; De León, B.; Almanza, M.; Vargas, G.; Izquierdo, M.; Font, O. Fly ash from a Mexican mineral coal I: Mineralogical and chemical characterization. J. Hazard. Mater. 2010, 181, 82-90. https://doi.org/10.1016/j.jhazmat.2010.04.096

[4] Sočo, E.; Kalembkiewicz, J. Investigations of sequential leaching behaviour of $\mathrm{Cu}$ and $\mathrm{Zn}$ from coal fly ash and their mobility in environmental conditions. J. Hazard. Mater.2007, 145, 482-487. https://doi.org/10.1016/j.jhazmat.2006.11.046 
[5] Terzić, A.; Pavlović, L.; Miličić, L. Evaluation of lignite fly ash for utilization as component in construction materials. Int. J. Coal Prep. Util.2013, 33, 159-180. https://doi.org/10.1080/19392699.2013.776960

[6] Chen, X.; Lu, A.; Qu, G. Preparation and characterization of foam ceramics from red mud and fly ash using sodium silicate as foaming agent. Ceram. Int.2013, 39, 1923-1929. https://doi.org/10.1016/j.ceramint.2012.08.042

[7] Terzić, A.; Andrić, L.; Mitić, V. Mechanically activated coal ash as refractory bauxite shotcrete microfiller: Thermal interactions mechanism investigation. Ceram. Int.2014, 40, 1205512065. https://doi.org/10.1016/j.ceramint.2014.04.045

[8] Yilmaz, A.; Degirmenci, N. Possibility of using waste tire rubber and fly ash with Portland cement as construction materials. Waste Manag.2009, 29, 1541-1546.

https://doi.org/10.1016/j.wasman.2008.11.002

[9] Erol, M.; Küçükbayrak, S.; Ersoy-Mericboyu, A. The influence of the binder on the properties of sintered glass-ceramics produced from industrial wastes. Ceram. Int.2009, 35, 2609-2617. https://doi.org/10.1016/j.ceramint.2009.02.028

[10] El-Didamony, H.; Abd El-Rahman, E.; Osman, R.M. Fire resistance of fired clay bricks-fly ash composite cement pastes. Ceram. Int.2012, 38, 201-209.

https://doi.org/10.1016/j.ceramint.2011.06.050

[11] Mukhopadhyay, T.K.; Ghosh, S.; Ghosh, J.; Ghatak, S.; Maiti, H.S. Effect of fly ash on the physico-chemical and mechanical properties of a porcelain composition. Ceram. Int.2010, 36, 1055-1062. https://doi.org/10.1016/j.ceramint.2009.12.012

[12] Chandra, N.; Sharma, P.; Pashkov, G.L.; Voskresenskaya, E.N.; Amritphale, S.S.; Baghel, N.S. Coal fly ash utilization: Low temperature sintering of wall tiles. Waste Manag.2008, 28, 1993-2002. https://doi.org/10.1016/j.wasman.2007.09.001

[13] Snelson, D.G.; Kinuthia, J.M. Characterisation of an unprocessed landfill ash for application in concrete. J. Environ. Manage.2010, 91, 2117-2125.

https://doi.org/10.1016/j.jenvman.2010.04.015

[14] Kılıç, A.; Atiş, C.D.; Yaşar, E.; Özcan, F. High-strength lightweight concrete made with scoria aggregate containing mineral admixtures. Cem. Concr. Res.2003, 33, 1595-1599. https://doi.org/10.1016/S0008-8846(03)00131-5

[15]Bentur, A.; Igarashi, S.; Kovler, K. Prevention of autogenous shrinkage in high-strength concrete by internal curing using wet lightweight aggregates. Cem. Concr. Res.2001, 31, 15871591. https://doi.org/10.1016/S0008-8846(01)00608-1

[16] Kim, Y.J.; Choi, Y.W.; Lachemi, M. Characteristics of self-consolidating concrete using two types of lightweight coarse aggregates. Constr. Build. Mater.2010, 24, 11-16.

https://doi.org/10.1016/j.conbuildmat.2009.08.004

[17] Gesoğlu, M.; Güneyisi, E.; Özturan, T.; Öz, H.Ö.; Asaad, D.S. Self-consolidating characteristics of concrete composites including rounded fine and coarse fly ash lightweight aggregates. Compos. Part B Eng. 2014, 60, 757-763.

https://doi.org/10.1016/j.compositesb.2014.01.008 
[18] Kayali, O. Fly ash lightweight aggregates in high performance concrete. Constr. Build. Mater.2008, 22, 2393-2399. https://doi.org/10.1016/j.conbuildmat.2007.09.001

[19] GÖRHAN, G.; KAHRAMAN, E.; BAŞPINAR, M.S.; Demir, İ. Uçucu Kül Bölüm I: Oluşumu, Sınıflandırılması ve Kullanım Alanları. Yapı Teknol. Elektron. Derg.2008, 4, 85-94.

[20] Singh, M.; Siddique, R. Effect of coal bottom ash as partial replacement of sand on properties of concrete. Resour. Conserv. Recycl.2013, 72, 20-32. https://doi.org/10.1016/j.resconrec.2012.12.006

[21] Cheeseman, C.R.; Virdi, G.S. Properties and microstructure of lightweight aggregate produced from sintered sewage sludge ash. Resour. Conserv. Recycl.2005, 45, 18-30. https://doi.org/10.1016/j.resconrec.2004.12.006

[22] Ramamurthy, K.; Harikrishnan, K.I. Influence of binders on properties of sintered fly ash aggregate. Cem. Concr. Compos. 2006, 28, 33-38.

https://doi.org/10.1016/j.cemconcomp.2005.06.005

[23] Kockal, N.U.; Ozturan, T. Characteristics of lightweight fly ash aggregates produced with different binders and heat treatments. Cem. Concr. Compos. 2011, 33, 61-67. https://doi.org/10.1016/j.cemconcomp.2010.09.007

[24] Cheeseman, C.R.; Sollars, C.J.; McEntee, S. Properties, microstructure and leaching of sintered sewage sludge ash. Resour. Conserv. Recycl.2003, 40, 13-25.

https://doi.org/10.1016/S0921-3449(03)00022-3

[25] Geetha, S.; Ramamurthy, K. Properties of sintered low calcium bottom ash aggregate with clay binders. Constr. Build. Mater.2011, 25, 2002-2013.

https://doi.org/10.1016/j.conbuildmat.2010.11.051

[26] Manikandan, R.; Ramamurthy, K. Effect of curing method on characteristics of cold bonded fly ash aggregates. Cem. Concr. Compos.2008, 30, 848-853.

https://doi.org/10.1016/j.cemconcomp.2008.06.006

[27] Baykal, G.; Döven, A.G. Utilization of fly ash by pelletization process; theory, application areas and research results. Resour. Conserv. Recycl.2000, 30, 59-77. https://doi.org/10.1016/S0921-3449(00)00042-2

[28] Johnsen, H.; Helland, S.; Hemdal, E. Construction of Stovset Free Cantilever Bridge and the Nordhordland Cable Stayer Bridge. In Proceedings of the Proceedings of International symposium on structural lightweight aggregate concrete. Sandefiord; 1995; pp. 373-379.

[29] Lee, H.-K.; Kim, H.-K.; Hwang, E.A. Utilization of power plant bottom ash as aggregates in fiber-reinforced cellular concrete. Waste Manag. 2010, 30, 274-284.

https://doi.org/10.1016/j.wasman.2009.09.043 